\title{
About PSD2 and Open Banking: Opportunities and Challenges
}

\author{
Chief Assist. Prof. Plamen Dzhaparov PhD \\ University of Economics - Varna, Varna, Bulgaria \\ pl.djaparov@ue-varna.bg
}

\begin{abstract}
It is no secret that nowadays customers are less and less dependent on one bank for all their financial needs. Many of them use a number of service providers, including Fintech companies, financial planners, mortgage brokers and insurers, all of which require a certain level of access to their personal financial data. Therefore, issues concerning the transfer of consumer data between different market participants come to the forefront of the regulatory authorities' agenda. Among the most important regulatory documents here is the Second EU Payment Services Directive PSD2, laying the foundations of Open banking. Although there are a number of ambiguities and difficulties regarding the actual application of Open Banking, it promises many benefits for both banks and their non-banking competitors, and last but not least - for customers and other key stakeholders.
\end{abstract}

Keywords: PSD2, Open Banking, banks, FinTech, Third Party Providers, Application Program Interface.

JEL Code: G21 DOI: https://doi.org/10.36997/IJUSV-ESS/2020.9.1.179

\section{Въведение}

Вън от всякакво съмнение е, че в последните няколко години сме свидетели на фундаментална и безпрецедентна промяна едновременно на технологията и философията на банкирането, която поразява мълниеносно всеки един елемент от стойностната верига на кредитните институции. На водещо място сред актуалните тенденции се нарежда трансформацията на финансовия ландшафт, вследствие появата на нови пазарни участници и доставчици на услуги, допълнена от все по-силната обвързаност и зависимост между отделните играчи. Разнообразието от нови пазарни участници и техният бърз растеж все повече мотивират регулаторните органи да налагат правила, насърчаващи конкуренцията чрез създаване на равнопоставеност, която да позволи на нови FinTech компании и други трети страни да навлязат в орбити, традиционно считани за „запазена територия“ на банките. Безспорно, сред най-важните регулации в това отношение е ревизираната директива за платежни услуги (Рayment Services Directive 2, PSD2) - ключова регулаторна инициатива на $\mathrm{EC}$, имаща за цел да улесни иновациите и стимулира конкуренцията на пазара на платежни услуги, като паралелно с това засили защитата на потребителите и подобри сигурността на интернет плащанията и достьпа до сметките ЕС и ЕИП. Най-фундаменталната промяна в директивата е обстоятелството, че тя задължава банките да отворят достьпа до сметките на своите клиенти за лицензирани трети страни (Third Party Providers, TPPs) чрез достьпни в интернет среда приложни програмни интерфейси (Application Program Interface, APIs).

\section{PSD2 и отвореното банкиране - общи постановки}

През последните няколко години малко технологии привличат толкова внимание, колкото APIs, които „обещават“ в еднаква степен да трансформират клиентските изживявания и бизнес процесите. Най-просто казано, приложният програмен интерфейс представлява „код, който дава възможност на две приложения да „разговарят“ помежду си, като същевременно позволява основните функции да останат скрити от потребителя“ (Nielsen et al., 2018, p. 9). Отворените интерфейси се прилагат от компании като Facebook, Google, Amazon и Airbnb в продължение на много години. Именно благодарение на тях корпорациите могат да предлагат редица услуги, които иначе не биха могли да развият 
сами. ${ }^{1}$ На практика технологията се използва от десетилетия и в банките, но единствено за разработване на предназначени за вътрешна употреба приложения. Със задължителното изискване да отворят достъпа до сметките на своите клиенти за трети страни PSD2 коренно променя това. Водещата цел тук е въпросните TPPs да разполагат с лесен достьп до наличните в банката данни за текущите сметки на определен клиент и да могат да използват нейната инфраструктура. Така, базирайки се на информация за историята на транзакциите и модела на разходите на клиента, третите страни могат да извършват плащания или да предлагат алтернативни услуги. Важно уточнение тук е, че те могат да получат достьп до данни от банковите сметки на даден клиент, както и да задействат плащания от тях, само при условие че той предостави изрично разрешение за това. ${ }^{2}$

PSD2 регламентира два нови типа играчи на финансовия пазар: доставчици на услуги по иницииране на плащания (Payment Initiation Services Providers, PISPs) и доставчици на услуги за предоставяне на информация за сметка (Account Information Service Providers, AISPs). Ролята на първите е да предоставят услуга, при която се инициира плащане по искане на ползвателя на платежни услуги по отношение на сметка, поддържана при друг доставчик (обикновено банка). Този вид услуга има значение за плащанията при електронната тьрговия, като се създава софтуерна връзка между интернет страницата на тьрговеца и платформата за онлайн банкиране на доставчика на платежни услуги, обслужващ сметката на платеца, с цел иницииране на плащания въз основа на кредитен превод. Така PISPs предлагат на потребителите възможност за пазаруване онлайн, дори ако те не разполагат с платежни карти. От своя страна, вторият тип участници могат да предоставят обобщена онлайн информация за една или повече платежни сметки, поддържани от ползвателя на платежни услуги при един или повече доставчици. На практика те могат да анализират покупателните навици на потребителя или да събират на едно място информацията за сметките в различни банки на един и същ потребител.

Дотук става ясно, че PSD2 позволява на редица оторизирани доставчици на дигитални продукти и услуги от различен тип (BigTech и FinTech компании, дигитални стартъпи, телекомуникационни фирми и т.н.) да навлязат активно в сферата на платежните системи, традиционно считана за изключителна привилегия за утвърдените банкови институции. Това ще им даде възможност да реализират на пазара новаторски и лесни за използване цифрови платежни услуги и да предоставят на потребителите и търговците на дребно ефективни, удобни и сигурни начини за плащане в рамките на ЕС. В резултат на това, вероятно не е далеч времето, в което „Facebook или Google например масово ще бъдат използвани за плащане на сметки, извършване на парични трансфери или анализ на разходите, докато парите на клиента продължават да се съхраняват на сигурно място в банковата му сметка“ (Evry, 2019). В този смисьл новата директива за платежните услуги проправя пътя на т.нар. отворено банкиране ${ }^{3}$ (Open Banking), заради което редица анализатори я определят за

\footnotetext{
${ }^{1}$ Uber e най-добрият пример тук: компанията използва Google карти и техния отворен интерфейс, в резултат на което успява да приложи идеята за създаване на превозваческа фирма, която не разполага нито със собствени таксита, нито с таксиметрови шофьори. Освен това шофьорите на Uber не трябва да познават града, в който работят, защото маршрутът бива предложен от приложението (KPMG, 2019, p. 10).

${ }^{2}$ Макар че крайната дата за влизане в сила на всички параметри на PSD2 е 14 септември 2019 г., на практика изискванията за междусистемен интерфейс, свързващ доставчиците на платежни услуги и банките, стават задължителни шест месеца по-рано. Проучване на 10 пазара в ЕС обаче констатира, че банките изпитват сериозни затруднения с крайния срок за имплементиране на изискванията на директивата. Към 14 март едва $59 \%$ от европейските банки са отворили своите портали за трети страни. Докато държави като Белгия, Финландия, Германия и Швеция имат високи нива на съответствие (над 80\%), в други като Дания, Франция, Норвегия и Испания по-малко от 50\% от банките са успели да спазят разпоредбите в срок (Tink, 2019).

3 Отвореното банкиране е широко понятие, което обхваща всички процеси, технологии и свързани услуги и продукти, обединени от един общ знаменател - отворените програмни приложни интерфейси, които позволяват достъп до някои от данните, събирани от банките, за да могат други компании да създават базирани на тях нови
} 
знакова и „сеизмична“, изразявайки очаквания тя да се превърне в катализатор на потенциална революция в банкирането на дребно.

Доколко реалистична е тази прогноза е въпрос на бъдещи оценки, но несъмнено PSD2 има потенциала да трансформира стойностната верига на разплащанията, да промени разбирането за това кои бизнес модели са печеливши и да завиши значително очакванията на клиентите. Според преобладаващите мнения всички заинтересовани страни ще извлекат ползи от отвореното банкиране. За индивидуалните клиенти те ще се изразяват в: по-голям избор на доставчици на финансови решения; получаване на персонализирани и интуитивни услуги на по-ниски цени; по-качествено обслужване и по-висока удовлетвореност; по-добра защита на техните интереси и лични данни; повишаване на финансовата грамотност; ускоряване процеса на създаване на иновации във финансовата сфера. Благодарение на PSD2 потребителите също така биха могли много по-лесно да наблюдават офертите на отделните доставчици и да „превключват“ между тях в зависимост от промоционалните условия, пониските транзакционни такси или осигурените по-високи лихви по техните спестявания. В допълнение към тези ползи, бизнес клиентите ще разполагат с инструментариум за рационализиране на финансовите операции, подобряване на паричните потоци и финансовото управление и по-добро разбиране за това как, кога и къде техните клиенти харчат парите си. Сред най-печелившите от директивата безспорно са FinTech компаниите и други подобни организации, които ще получат достьп до банковите данни на клиентите и ще могат да им оферират иновативни продукти и услуги, без да е необходимо да изграждат собствени сложни инфраструктури. Ползи ще има и за регулаторите, тъй като отвореното банкиране подобрява прозрачността и им дава възможност да наблюдават участниците и движението на данни, за да гарантират, че всички страни (и най-вече клиентите) остават защитени (FDATA North America, 2019, pp. 11-17). Въпреки че на пръв поглед традиционните банки изглеждат като големия губещ от Open Banking, те също биха могли да реализират редица ползи, които са анализирани подробно по-напред в изложението.

Следва да се отбележи, че новата европейска директива въвежда и някои други ключови промени, засягащи банките. Така например, с цел подобряване сигурността за ползвателите на платежни услуги, осъществявани в интернет или по друг дистанционен способ, кредиторите вече са длъжни да следват подход на „защита в дълбочина“. Той се изразява в прилагане на няколко контролни механизми, обхващащи един и същ риск, например принципа на четирите очи, двуфакторно удостоверяване на идентичността, сегментация на мрежата и множество защитни стени. Сред най-важните изисквания тук е банките да извършват по-задълбочено установяване на идентичността на клиента (Strong Customer Authentication) всеки път, когато платец нареди електронна транзакция. То включва използване на поне два елемента за идентификация, категоризирани като знание (нещо, което само ползвателят знае), притежание (нещо, което само той притежава) и характерна особеност (нещо, което го характеризира). При това тези елементи следва да са независими, така че нарушаването на един от тях да не влияе върху надеждността на останалите. ${ }^{4}$

\section{2. Банките и PSD2 - между заплахите и ползите}

На този фон става ясно, че PSD2 без съмнение ще рефлектира сериозно върху бизнеса на традиционните банкови институции. Освен неизбежната загуба на монопола над информацията за клиентските сметки, някои виждат два основни начина за редуциране на

продукти и услуги (KPMG, 2019, р. 10). Други дефинират ключовото понятие още по-лаконично „структурирано споделяне на данни между доставчици на финансови услуги, основано на нуждите и съгласието на техните общи клиенти“ (FDATA North America, 2019, p. 5).

${ }^{4}$ Макар че първоначално тези изисквания също са с краен срок 14 септември 2019 г, впоследствие ЕБО удължава срока за прилагане на задълбочено установяване на идентичността на клиента при платежни операции с карти в интернет до 31 декември 2020 г. 
банковите приходи под въздействие на директивата. Пьрво, позволявайки на трети страни да инициират плащания от името на клиента, PSD2 би могла да промени традиционния модел на разплащания, базиран на дебитните и кредитни карти. ${ }^{5}$ Второ, директивата има потенциала да прекъсне традиционните банкови взаимоотношения. По-конкретно, агрегирането на финансовите услуги става все по-важно в отвореното банкиране и от тази гледна точка кредиторите могат да загубят близостта на клиентите, които все по-често ще управляват финансите си чрез приложения, предоставени от трети страни. Това би могло да намали редовното пряко взаимодействие с тях и да повлияе отрицателно върху способността на банките да прилагат спрямо своите най-доходоносни продукти стратегии за кръстосани и форсирани продажби (S\&P Global Ratings, 2019, р. 6). Според други мнения, директивата заплашва кредитните институции с промяна на мястото им в стойностната верига на финансовите услуги. По-конкретно, в случай че не реагират бързо на PSD2, те ще изгубят ролята си на дистрибутори посредством своите интерфейси и ще бъдат принудени да се задоволят единствено с позицията на производители на продукти и услуги. От Deloitte допълват още, че не е за подценяване и потенциалната редукция на приходи вследствие заложеното в регулацията намаление на транзакционните такси, появата на нови пазарни играчи и очакваното отдръпване на потребителите от кредитните карти (Deloitte, 2019, p. 12).

Друг проблем за банките е, че целейки насьрчаване на конкуренцията, новата европейска директива всъщност ги поставя (поне донякъде) в неравностойно положение. Това е така, понеже те ще продължават да бъдат отговорни за поне някои от рисковете, засягащи клиентските лични данни и начина, по който те се третират от небанковите доставчици, но в същото време няма да могат да се възползват от реципрочно задължение за тези трети страни да споделят своите собствени данни. В допълнение, отварянето на банковите интерфейси към финтех компаниите може да доведе до зачестяване на пробивите в системите, изтичането на лични данни и кибератаките (EY, 2019, p. 2).

Изискванията за задълбочена идентификация на платеца генерират още трудности. Така например, разходите за проектиране, внедряване и одитиране на процедурата по „разпознаване“ на клиента се поемат от доставчиците на платежни услуги, обслужващи неговата сметка, т.е. банките. Същевременно, доставчиците на услуги за иницииране на плащания и фирмите, предоставящи информация за сметки, трябва да гарантират правилното прилагане на автентикацията на клиента, като разчитат на процедурата за удостоверяване, предоставена от кредитните институции. В този смисъл изискванията на директивата поставят пред банките както технически, така и търговски предизвикателства (Ley, Bailey and Gallo, 2016). От техническа гледна точка те трябва да гарантират, че разполагат с две отделни приложения/канали за независимо иницииране на плащания и генериране на елементи за удостоверяване, което, разбира се, води до допълнителни IT разходи. Освен това, всички потребители ще трябва да предоставят електронни пълномощни, преди банките да отворят достьпа до техните данни за трети страни. За тази цел те трябва да могат да издават подобни документи, да ги съхраняват и при всяка една транзакция да могат да проверяват дали те са валидни (CIO, 2019). Търговските предизвикателства пък най-общо опират до това как всички изискуеми промени да се случат по удобен за потребителя начин, възможно най-евтино и по-добре от конкурентите.

На фона на казаното дотук не е учудващо, че някои виждат и сериозни противоречия между изискванията на PSD2 и GDPR, породени от различните отправни точки при

\footnotetext{
5 Въпреки значимостта на тази заплаха, авторите констатират, че растежът на картовите плащания в Европа е силен през последните години и вероятно ще остане устойчив за известно време. Потребителите в общия случай смятат, че плащанията с кредитни карти са достатъчно удобни, което ще ги дестимулира да преминат бързо към алтернативни мобилни платежни услуги. За да могат подобни услуги да имат съществен ефект върху банковите приходи от разплащания, ще трябва да настъпи фундаментална промяна в поведението на потребителите в повечето европейски страни, което е малко вероятно през следващите пет години.
} 
разработването на двата регламента. Докато директивата за платежните услуги „отваря“ банковия пазар, насърчавайки конкуренцията и иновациите в различни продукти и услуги, всеки достъп до такива трябва да е в съзвучие със строгите разпоредби на GDPR. Taка се създава непосредствено напрежение между разширения достъп до клиентските данни и тяхната защита, и се повдигат логични въпроси относно отговорността при възникнали нарушения на данните. Този проблем може да се изостри, заради все още ниската обществена информираност за начина, по който работи технологията зад отвореното банкиране, тъй като тя може да доведе до страх и несигурност сред клиентите по повод използването на техните данни в контекста на Open Banking. В допълнение, паралелното действие на PSD2 и GDPR изисква непрекъсната и тясна координация между ръководителите на бизнес процесите, контрола, риск мениджмънта и IT отделите, което наслагва още един слой на бюрократичност и генерира допълнителни разходи за банките. В крайна сметка, „ако съблюдаването на правилата за поверителност на данните стане твърде обременяващо, това би могло да компрометира отвореното банкиране или да действа като сериозна бариера пред навлизането на нови участници на пазара. Ето защо един от ключовите бъдещи ангажименти на регулаторните органи трябва да бъде възможно най-умелото управление на компромиса между сигурността и отвореността“" (ЕY, 2019, p. 11). ${ }^{6}$

Разбира се, освен „потьрпевши“, банките също така могат да бъдат бенефициенти на Open Banking. Така например самите те имат възможност да използват данни и услуги, предоставяни от други банки посредством техните отворени приложни интерфейси. Това им дава достьп до още повече информация за клиентите - познания не само за използваните от тях услуги при конкурентите, но и за извършваните платежни операции. Ефектите могат да бъдат двойни. От една страна, трезорите ще се опитат да привлекат клиенти, като оферират продукти, сходни на конкурентните, а от друга - с по-добро познаване на техните навици, начин на живот, цели и желания, може да се очаква да предложат нови по-персонализирани и атрактивни продукти и услуги. На практика това вече се случва в по-големите банки, които добавят в приложенията си за мобилно банкиране нова функционалност - информация и достьп до всички сметки на клиента във всички институции.

В по-дългосрочен план Open Banking предоставя възможности за кредиторите да преоценят и оптимизират бизнес моделите си, както и състоянието на своята киберсигурност. Като друга ключова полза се сочи насьрчаването на партньорства с иновативни доставчици на платежни услуги, в рамките на които банките могат да се възползват от тяхната висока техническа ескпертиза и експериментаторски дух. Нещо повече - очакванията са „с помощта на отвореното банкиране по същество банката да се превърне в платформа, около която трети компании могат да изграждат приложения. Това интегрира банкирането дълбоко в дигиталната екосистема, като го прави безпроблемно изживяване за клиента“" (Oracle, 2017, p. 2). Други очакват PSD2 да съдейства за намаляване на разходите за извършваните разплащания и съкращаване на времето за сетълмент (Nielsen et al., 2018, p. 10).

В друга студия се извеждат четири основни ползи за банките (Waldschmidt, Genthner and Cortet, 2019, pp. 80-81):

Първо, отвореното банкиране дава възможност за истинско клиентско центриране, което на свой ред позволява т.нар. контекстуално обслужване ${ }^{7}$ и повишава квотата на клиентско задържане. Това става по два начина. От една страна, банките могат да използват отворените интерфейси на конкурентите, за да интегрират предлагани от тях нови продукти

\footnotetext{
${ }^{6}$ Следва да се отчетат обаче и други мнения, според които GDPR и PSD2 не са в директно „съревнование“. В крайна сметка приоритетите на отвореното банкиране са осигуряване на прозрачност, връщане на контрола в ръцете на клиента и сигурно споделяне на информацията - все принципи, заложени в GDPR (Erskine-Fox, 2019). ${ }_{7}$ Ако клиентите търсят напр. недвижими имоти, банката може да вгради ипотечните си услуги в платформа за недвижими имоти, за да създаде точки за контакт с тях извън традиционните банкови канали.
} 
в своите стойностни оферти. А от друга - налице са възможности за базирана на API дистрибуция на продукти и услуги директно в точката на продажба.

Второ, благодарение на собствените си програмни приложни интерфейси банките могат да реализират и преки финансови изгоди. Така например те биха могли да предлагат продукти и услуги, за използването на които заинтересованите трети страни трябва да заплащат такси.

Трето, чрез прилагането на базирана на API вътрешна инфраструктура банките могат да повишат оперативната си ефективност. Това става чрез автоматизация на процесите, съкращаване на времето и разходите за изследвания и развитие, както и по-лесен и бърз обмен на ценни информационни ресурси. Освен това, благодарение на подобреното управление на достьпа може да бъде повишена и сигурността.

Четвърто, иновациите се ускоряват чрез улесняване на сътрудничеството и комуникацията с трети страни. С други думи, банките с отворена и иновативна организация ще печелят от трансфера на знания в рамките на все по-активните си бизнес партньорства.

На този фон според някои прогнози до края на 2020 г. 61 млрд. евро (или 7\% от общата сума на банковите приходи в Европа) ще бъдат генерирани от дейности, свързани с отвореното банкиране (Accenture, 2018, p. 5). Следва да се има предвид обаче, че макар официално PSD2 вече да е в сила, нейното действително въздействие върху пазара на платежни услуги все още не може да се оцени категорично. Какъв ще бъде позитивният ефект от нея за банките и може ли да се очаква компрометиране на техния монопол в определени области на Retail Banking, към днешна дата са въпроси с повишена степен на трудност. Отговорът им не е еднозначен, най-малкото поради факта, че в средно- и дългосрочен план реалният ефект от директивата ще бъде силно зависим от два фактора начинът, по който самите банки реагират на нея и склонността на потребителите да споделят информация за своята сметка с други банки и трети страни.

За да се потърси отговор на тези въпроси в последните години се инициират редица изследвания сред европейските банки и потребители. В мащабно проучване на Deloitte, обхващащо 90 кредитни институции в 17 страни, се установява, че отношението на различните банки към директивата варира в много широки граници. Например, докато големите западноевропейски играчи я разглеждат повече като възможност и са настроени да следват по-агресивен подход, насочен към придобиване на пазарен дял, то в ЦИЕ ситуацията е по-различна. Тук се разграничават две отделни категории кредитни институции, условно обозначени като „Challengers“ и „Minimalists“. Пьрвите, доминирани от големи универсални банки, са по-отворени към възможностите, произтичащи от директивата и често са насочени към кооперативна стратегия, включваща и трети страни. На свой ред, минималистите, представени предимно от средни и по-малки играчи, следват защитен подход, ограничен единствено до спазване на правилата, или пък все още не разполагат със собствена стратегия, а вместо това са в изчаквателна позиция ("wait and see“). Не е изненада също така, че напредъкът на предприетите от банките инициативи по PSD2 до голяма степен корелира с разпределените бюджети и с размера на институцията.

Като общ проблем при всички банки се изтьква обстоятелството, че досега те са отделяли най-много ресурси за реагиране на PSD2 от Compliance-гледна точка, а не от стратегическа перспектива. ${ }^{8}$ Този извод се потвърждава и от изследване на Innopay, което констатира, че $76 \%$ от банките в общността не отиват отвъд изискванията на директивата

\footnotetext{
8 От консултантската компания коментират, че този проблем може да се дължи на факта, че много банки виждат PSD2 като средно- до дългосрочна тенденция, на която следва да се отговори с адекватна стратегия, но в същото време повечето от тях не желаят непременно да бъдат първоначални „двигатели“ на този процес. На този фон банкерите очакват най-голямото въздействие на директивата да се усети между една и три години след влизането й в сила, т.е. общото схващане е, че тя няма да предизвика „голям взрив“, а по-скоро постепенни, но необратими ефекти.
} 
(Cortet and Tsovilis, 2019, p. 24). Липсата на ентусиазъм при възприемането на отвореното банкиране води дотам, че решените на всяка цена да спазят „буквата на закона“ Complianceекипи не отчитат крайната му цел и пренебрегват иновационните екипи, предоставящи визия за възможностите на PSD2 да обогати клиентските изживявания (Paysafe, 2018).

От гледна точка на засегнатите бизнес сфери, банките очакват регулацията да има най-голямо въздействие върху банкирането на дребно и МСП сегмента, а плащанията и потребителското кредитиране се дефинират като продуктовите категории, за които директивата генерира най-много възможности. Като значима заплаха пък се отбелязва обстоятелството, че по-широкото използване на AISP и PISP услуги ще повиши прозрачността по отношение на таксите и възвръщаемостта, и в същото време ще осигури лесни начини за прехвърляне на сметки към конкурентите. Очаква се и по-голяма волатилност при депозитите, както и проблеми при картовия бизнес. Резултатите от друго проучване потвърждават основното притеснение на банкерите - за потребителя може би вече няма да е от съществено значение кой точно му предоставя дадена услуга, стига тя да е найподходящата за него. В този смисъл $56 \%$ от респондентите вярват, че клиентската лоялност спрямо банките ще намалее драстично (Tink, 2019).

Въпреки това много от кредиторите отбелязват, че някои негативни въздействия от директивата могат да бъдат смекчени благодарение на предоставяни от самите тях иновативни услуги, чрез които да се генерират нови приходи или да се привлекат клиенти. ${ }^{9}$ Ето защо около половината от участващите в проучването на Deloitte банки планират да станат доставчик на услуги за иницииране на плащания и/или доставчик на услуги за предоставяне на информация за сметки. Важно е да се отбележи също така, че повече от $30 \%$ от респондентите проявяват интерес към партньорства с FinTech компании или други трети страни. Донякъде изненадващо, проучването установява още, че дори след PSD2 BigTech коропорациите като Google и Amazon все още не се възприемат като голяма заплаха за банките, въпреки доказаните им способности да предизвикват значителни промени на пазара на разплащателни услуги.

В крайна сметка, резултатите от различни проучвания дават основание на някои да констатират, че макар PSD2 да има за цел увеличаване на конкуренцията и улесняване на новите пазарни участници, е твърде възможно съществуващите големи банки да продължат да „улавят“ и консолидират пазара и в бъдеще (Deloitte, 2018a, p. 42). Потвърждение за тази констатация намираме във Великобритания. В статия във FT със заглавие „Британските challenger banks „Увяхват“ в битката с големите четири“ се посочва, че концентрацията на открити сметки в четирите най-големи кредитора на Острова HSBC, Lloyds, Royal Bank of Scotland и Barclays в последните години дори нараства. В същото време ситуацията при новите пазарни участници не е обнадеждаваща. Така например, вследствие на сериозен спад на цените на акциите на една от големите необанки Metro Bank през септември 2019 г. анализаторите я определят като потенциална мишена за поглъщане (Megaw, 2019).

Изследванията на нагласите на европейските потребители спрямо PSD2 също установяват интересни тенденции и закономерности. Така например, само $26 \%$ от клиентите в ЦИЕ биха се чувствали комфортно да споделят информация за сметката си с банкова институция, различна от тяхната основна банка (Deloitte, 2018b, p. 4). Според друго

\footnotetext{
9 В тази връзка, други скорошни проучвания сред финансовите ръководители в Европа показват, че отношението им към отвореното банкиране се е променило значително през последните няколко години и първоначалната съпротива все повече се превръща в приемане. 64\% от респондентите в изследване на Tink например считат, че финансовата индустрия ще се развие значително в резултат на отвореното банкиране, като $55 \%$ от тях са настроени изцяло позитивно към настьпващите промени срещу едва 15\% с ясно изразени негативни нагласи (Tink, 2019, p. 4). Подобно, 65\% от анкетираните от Accenture виждат отвореното банкиране повече като възможност, отколкото като заплаха, 52\% го разглеждат като начин да се разграничат от традиционните си конкуренти, а $99 \%$ планират да направят големи инвестиции в инициативите за отворено банкиране до 2020 г. (Accenture, 2018, p. 5).
} 
проучване само половината от клиентите на Обединеното кралство биха дали на своята банка мобилния си телефон, за да може тя да се съобрази с изискванията за по-дълбочинно удостоверяване на самоличността. Този процент е още по-нисък за потребителите на възраст 18-24 години (FICO, 2019). Без съмнение основният фактор за тази неувереност в потребителите е ниската им информираност относно директивата. Така например, според проведено в 11 европейски страни проучване на MasterCard, 85\% от европейците не са запознати с инициативата за отворено банкиране (MasterCard, 2019). ${ }^{10}$

С други думи, оказва се, че въпреки обема на изследванията, посветени на PSD2, понастоящем разбирането на клиентите е на много примитивен етап. Тъй като отключените благодарение на директивата нови продукти и услуги все още не са масово на пазара, съзнанието на потребителите е „моноползирано“ от негативния контекст, фокусиран предимно върху въпросите относно сигурността (Paysafe, 2018). Това еднозначно показва, че ако искат да извлекат реални ползи от отвореното банкиране, както банките, така и третите страни, трябва да мислят далеч отвъд техническите параметри и да се насочат активно към информиране и образоване на потребителите.

\section{3. Отвореното банкиране във и извън Европа - сравнителна характеристика}

Следва да се има предвид, че отвореното банкиране не е „патент“ единствено на ЕС. Създаването на Open Banking стандарти е в ход по целия свят, на пазари като Индия, Китай, Япония, Австралия, САЩ, Мексико, Сингапур, Хонг Конг, Швейцария, Русия, Нигерия и други (FDATA North America, 2019, p. 6). Нещо повече - водени от потенциалната добавена стойност, банките започват все повече да се ангажират доброволно с отворено банкиране, дори в региони, където то все още не е част от регулаторните режими и рамки.

В разгара на развитието на Open Banking-екосистемата в различни части на света са налице разнообразни режими и подходи за нейното налагане и възприемане. В изследване на InnoРay се анализират 8 критерия, според които се разграничават отделните подходи (Mintjes and Cortet, 2019, pp. 11-13).

1) Инициатор - тук се поставя въпросът дали преходът към отворено банкиране е иницииран от регулаторите или от самите пазарни участници. Освен в Европа, първият подход е характерен и за Австралия, където през 2017 г. правителството обявява въвеждането на Закон за правата на потребителите (CDR). Отвореното банкиране е част от $\mathrm{CDR}$, като изискването е банките да започнат да предоставят данни на трети страни по искане на своите клиенти от февруари 2020 г. (Hacquebord et al., 2019, p. 6). В други региони (напр. Нова Зеландия, Сингапур и Китай) пазарните участници, обединени в браншови организации, започват да се организират доброволно. Дейностите включват разработване на пилотни проекти за Open Banking или публикуване на насоки за стандартизиране на приложните интерфейси. Задължителните регулации вероятно няма да са основополагащият фактор и в САЩ, предвид изразената от Министерството на финансите позиция, че основите на отвореното банкиране трябва да бъдат поставени от пазара, а не от правителството (U.S. Department of the Treasury, 2018). Американският банков сектор всьщност постепенно започва да признава необходимостта от отворено банкиране, за да бъде „в крак“ с европейските институции. Банките с опериращи в Европа клонове така или иначе трябва да отговорят на изискванията на PSD2, което вероятно ще доведе до натиск на пазара, подтиквайки и останалите американски банки да ги последват (Hacquebord et al., 2019, p. 6).

\footnotetext{
${ }^{10}$ В същото време обаче $43 \%$ биха приветствали услугите, „отключени“ от новата регулация. Докато $13 \%$ вече използват мобилни приложения, чрез които следят финансите си от множество банкови сметки, почти половината от респондентите биха го направили в бъдеще. Повече от една пета (22\%) биха предпочели услуга, която може да им помогне да управляват парите си и да прогнозират разходните модели въз основа на анализ на всичките им предишни разходи.
} 
2) Приложимост - обхватьт на отделните регулаторни режими е различен. Докато в EC PSD2 се простира върху всички Retail и Corporate банки, предлагащи платежни сметки достьпни онлайн, в Мексико например се обхващат всички финансови институции. В Австралия пък се предвижда на бъдещ етап, освен банките, задължени по закона да бъдат компаниите от телекомуникационния, застрахователния и енергийния сектор.

3) Стандартизация - в отделните юрисдикции са налице ключови разлики по отношение на стандартизацията на интерфейсите и контролите за сигурност. Най-общо регулаторите търсят компромиса между насърчаването на иновациите, позволявайки на пазара да разработва собствени решения, и осигуряването на равнопоставеност чрез налагане на общовалидни стандарти. Сингапур например използва доброволен, органичен подход, като през 2016 г. е публикуван документ, посветен на API-технологията, който да послужи като ориентир за банките (ABS and MAS, 2016). Идеята е те сами да решат дали доброволно да приемат местни стандарти или да разработват собствени интерфейси. В ЕС също виждаме пазарни инициативи (като стандарта на берлинската група и разработения от Словения и Франция STET), чиято цел е да запълнят празнината, оставена от липсата на конкретни изисквания за стандартизация на API в PSD2. Според редица анализи обаче липсата на единен стандарт в общността противоречи на духа на регулацията, насьрчаваща повече иновации, и се превръща в най-голямата пречка пред разгръщането на пълния потенциал на отвореното банкиране, тъй като води до фрагментация на пазара и понижава нивото на оперативна съвместимост (Ley, Scott and Gallo, 2018). Ето защо FCA във Великобритания например предприема по-регулиран подход и налага по-високо ниво на стандартизация, което позволява на третите страни по-лесно да се свързват с отворените банкови интерфейси. В Австралия пък специално създаден за целта орган насочва компаниите от различни сектори към създаване на общ стандарт, полагащ основите на междуотрасловия обмен на данни (CDS).

4) Обхват на услугите - всички разглеждани режими съдържат насоки и правила за разкриване на информация за поддържаните в банките клиентски сметки. Отделно, в ЕС, Великобритания, Япония и Нова Зеландия експериментират и с изисквания по отношение на инициирането на плащания. Някои страни заявяват, че предпочитат прилагането на поетапен подход, чрез който да се ограничи възникването на неоправдано високи рискове за сигурността.

5) Срокове - за регионите със задължителни изисквания по отношение на отвореното банкиране регулаторните органи определят срок между 18 и 24 месеца, в който банките трябва да се съобразят. В някои страни сроковете варират в зависимост от размера на институцията, като на по-малките банки се дава допълнително време, в което да почерпят опит от пазарните лидери. Във Великобритания например в първия етап само деветте найголеми банки трябва да отворят своите APIs, а в Австралия - четирите най-големи.

6) Търговски модел - повечето регулаторни режими лимитират транзакционните такси, които кредитните институции могат да изискват от третите страни за използване на техните интерфейси. Тези ограничения се проявяват най-вече в правила, задължаващи банките да предоставят недискриминационен достьп до клиентските данни. Австралия отива по-далеч в изискванията, като забранява начисляването на такива такси. В някои страни (например Сингапур, Япония и Индия) банките и третите страни свободно договарят условия за ценообразуване в своите двустранни споразумения.

7) Сигурност и достъпност - сред всички градивни елементи на Open Banking техническите стандарти за сигурност и достьпност остават най-слабо засегнати в различните регулаторни режими. Въпреки че регулаторните технически стандарти на PSD2 (RTS) са поподробни в сравнение с останалите региони, тяхното допълнително отлагане във времето може да предизвика смущения на пазара. Останалите юрисдикции не предоставят строги технически детайли и оставят разработването им на пазара. 
8) Лицензиране на третите страни - в повечето региони все още не е съвсем ясно как ще изглежда процедурата по лицензиране. ЕС и Австралия създават многостепенна система за акредитация, където акредитатор е съответно местният компетентен орган и Австралийската комисия за конкуренцията и потребителите (АССС). Хонконг пък използва различен подход, при който банките решават с коя трета страна да си сътрудничат, сключвайки за целта двустранни споразумения.

Тъй като отвореното банкиране все още е в начален стадий, на този етап е невъзможно да се установи кои са детерминантите, превръщащи определен режим в успешен. В потвърждение на тази констатация изследване на Ernst\&Young достига до извода, че пионерите в областта на Open Banking в глобален мащаб са Великобритания и Китай, които (с оглед на динамиката на местните пазари и културните особености) прилагат диаметрално противоположен подход при налагане на неговите принципи (Thomas, 2018). ${ }^{11}$ Ето защо е твърде малко вероятно с течение на времето да се възприеме единен регулаторен режим, който да „пасва“ на всички страни и региони.

\section{Заключение}

Насърчаването на конкуренцията и осигуряването на равни възможности за отделните пазарни участници се превръща във водещ приоритет за финансовите регулатори. Сред найважните стьпки в тази посока е ревизираната директива за платежните услуги на EC PSD2, която създава предпоставки за бурно развитие на отвореното банкиране. Не без основание традиционните банки изпитват сериозни притеснения от възможните последствия от директивата - загуба на монопола над информацията за клиентските сметки, трансформация на стойностната верига на разплащанията, редуциране на приходите, повишен риск от кибератаки и т.н. Успоредно с тези предизвикателства обаче банките съзнават, че PSD2 им „обещава“ и редица ползи - достьп до повече информация за „чуждите“ клиенти, възможност за преоценка и оптимизиране на бизнес модела, улесняване на партньорствата с иновативни доставчици на платежни услуги, повишаване на оперативната ефективност и пр.

Отвореното банкиране има потенциал да генерира ползи и за останалите ключови стейкхолдери. За клиентите например това са: по-голям избор на доставчици на финансови решения, ускоряване процеса на създаване на финансови иновации, получаване на персонализирани и едновременно с това по-евтини продукти и услуги, възможност за повишаване на финансовата грамотност и др. От гл.т. на регулаторите пьк отвореното банкиране подобрява прозрачността и им осигурява по-пълна и ясна картина за пазарните участници и движението на данни между тях. Всичко това води дотам, че след Европа Open Banking започва да си проправя път и в останалите части на света. И така, макар и в начален стадий на своето развитие, вече има ясни индикации, че в дългосрочен план отвореното банкиране разполага с потенциал за същинска трансформация на финансовия сектор.

\section{Използвана литература}

1. ABS (The Association of Banks in Singapore) and MAS (Monetary Authority in Singapore) (2016) Finance as a Service: API Playbook. [Online]. Available at: https://www.mas.gov.sg//media/MAS/Smart-Financial-Centre/API/ABSMASAPIPlaybook.pdf.

\footnotetext{
${ }^{11}$ Своеобразната класация консултантската агенция прави на базата на оценка влиянието на четири фактора: първо, доколко благоприятен е регулаторният пейзаж; второ, какъв е потенциалът на потребителите да възприемат отвореното банкиране с оглед на текущото им пазарно поведение; трето, чувстват ли се те достатъчно уверени да споделят своите данни с трети страни; четвърто, доколко надеждна е иновационната среда. Оказва се например, че единствено в Китай клиентите масово са склонни да предоставят банковите си данни в замяна на по-добри и качествени услуги, докато тези в Обединеното кралство и останалите 8 изследвани страни изпитват силни съмнения относно сигурността и защитата на личните им данни. Тези разминавания в нагласите обясняват защо във Великобритания отвореното банкиране е задвижвано от регулаторите, а в Китай от пазара.
} 
2. Accenture (2018) The brave new world of Open Banking. [Online]. Available at: https://www.accenture.com/t00010101T000000Z_w__gb-en/_acnmedia/PDF-71/AccentureBrave-New-World-Open-Banking.pdf\#zoom $=50$.

3. CIO (2019) 60\% ot evropeiskite banki veche sa otvorili portalite si spored iziskvaniiata na PSD2.

[Online].

Available

at:

https://cio.bg/analizi/2019/03/28/3431803_60_ot_evropeiskite_banki_veche_sa_otvorili_portali te/.

4. Cortet, M. and Tsovilis, J. (2019) INNOPAY Open Banking Monitor: Bank Moving Beyond PSD2 Requirements. In: The Paypers Open Banking Report 2019: Insights into the Global Open Banking Landscape, 24-27. [Online]. Available at: https://thepaypers.com/reports/the-openbanking-report-2019-insights-into-the-global-open-banking-landscape-2/r780814.

5. Deloitte (2018a) European PSD2 Survey: Voice of the Banks. [Online]. Available at: https://www2.deloitte.com/content/dam/Deloitte/ce/Documents/financial-services/ce-deloitteeuropean-psd2-voice-of-banks-survey-2018.pdf.

6. Deloitte (2018b) CEE PSD2 Survey: Voice of the Customer. [Online]. Available at: https://www2.deloitte.com/content/dam/Deloitte/ce/Documents/financial-services/ce-psd2-

voice-of-the-customer-survey-2018.pdf.

7. Deloitte (2019) Breaking down this year's federal banking regulations. Deloitte Banking regulatory outlook 2020. [Online]. Available at: https://www2.deloitte.com/us/en/pages/regulatory/articles/banking-regulatory-outlook.html.

8. Ernst\&Young (EY) (2019) Preparing for regulation in the digital age. EY 2019 Global bank regulatory outlook. [Online]. Available at: https://assets.ey.com/content/dam/ey-sites/eycom/en_gl/topics/banking-and-capital-markets/ey-2019-global-bank-regulatory-outlookpreparing-for-regulation-in-a-digital-age.pdf.

9. Erskine-Fox, E. (2019) One year on: Impact of the GDPR on Digital Banking. International Banker. [Online]. Available at: https://internationalbanker.com/finance/one-year-on-the-impactof-the-gdpr-on-digital-banking/.

10. Evry (2019) PSD2 - the directive that will change banking as we know it. [Online]. Available at: https://www.evry.com/en/about-evry/media/news/2019/06/psd2-the-directive-that-willchange-banking-as-we-know-it/.

11. FDATA North America (2019) Opportunities in Open Banking. [Online]. Available at: https://fdata.global/north-america/wp-content/uploads/sites/3/2019/04/FDATA-Open-Bankingin-North-America-US-version.pdf.

12. FICO (2019) FICO Survey: UK Consumers Could Thwart Strong Customer Authentication. [Online]. Available at: https://www.fico.com/en/newsroom/fico-survey-uk-consumers-couldthwart-strong-customer-authentication.

13. Hacquebord, F., McArdle, R., Mercês, F. and Sancho, D. (2019) Ready or Not for PSD2: The Risks of Open Banking. TREND Micro. [Online]. Available at: https://documents.trendmicro.com/assets/white_papers/wp-PSD2-The-Risks-of-OpenBanking.pdf.

14. KPMG (2019) PSD2 and Open Banking: Revolution or evolution? [Online]. Available at: https://assets.kpmg/content/dam/kpmg/pl/pdf/2019/04/pl-Raport-PSD2-i-Open-BankingENG.pdf.

15. Ley, S., Bailey, S. and Gallo, V. (2016) PSD2 RTS on authentication and communication: The devil is in the (lack of) details. Deloitte. [Online]. Available at: https://blogs.deloitte.co.uk/financialservices/2016/09/psd2-rts-on-authentication-andcommunication-the-devil-is-in-the-lack-of-details.html.

16. Ley, S., Scott, A. and V. Gallo (2018) European Union: Baby Steps, But No Giant Leap: PSD2 At Six Months Old. Deloitte. [Online]. Available at: 
http://www.mondaq.com/uk/x/724162/Financial+Services/Baby+Steps+But+No+Giant+Leap+P $\mathrm{SD} 2+\mathrm{At}+\mathrm{Six}+$ Months+Old.

17. MasterCard (2019) Digital banking has become part of European's everyday life new study from Mastercard reveals. [Online]. Available at: https://newsroom.mastercard.com/eu/pressreleases/digital-banking-has-become-part-of-europeans-everyday-life-new-study-frommastercard-reveals/.

18. Megaw, N. (2019) UK's bank challengers are fading in fight with big four. Financial Times, 30.09.2019.

19. Mintjes, D. and Cortet, M. (2019) Open Banking: Key Decisions for the Future Ecosystem. In: The Paypers Open Banking Report 2019: Insights into the Global Open Banking Landscape, 10-18. [Online]. Available at: https://thepaypers.com/reports/the-open-banking-report-2019insights-into-the-global-open-banking-landscape-2/r780814.

20. Nielsen, T., Evstifeeva, P., Bedford, A. et al. (2018) Regulation driving banking transformation. Deutsche Bank. [Online]. Available at: https://cib.db.com/docs_new/GTB_Digital_Whitepaper.pdf.

21. Oracle (2017) Achieving a Head Start in the API Economy: How should banks prepare for the Open Banking Future? A Point of View by Oracle Financial Services. [Online]. Available at: https://www.oracle.com/webfolder/s/delivery_production/docs/FY16h1/doc1/Open-API.pdf.

22. Paysafe (2018) Are banks delivering the Open Banking we were promised? [Online]. Available at: $\quad$ https://www.paysafe.com/en/blog/are-banks-delivering-the-open-banking-we-werepromised/.

23. S\&P Global Ratings (2019) European Banks Face Risks In Race To Implement PSD2. [Online]. Available https://www.allnews.ch/sites/default/files/files/European\%20Banks\%20Face\%20Risks\%20In\% 20Race\%20To\%20Implement\%20PSD2_16\%20May\%202019.PDF.

24. Thomas, H. (2018) EY Open Banking Opportunity Index: where open banking is set to thrive. Ernst\&Young. [Online]. Availabe at: https://www.ey.com/en_gl/banking-capital-markets/eyopen-banking-opportunity-index-where-open-banking-is-set-to-thrive.

25. Tink (2019) Open Banking 2019: Inside the minds of Europe 's bankers. [Online]. Available at: https://hub.tink.com/hubfs/05\%20Resources/Reports/Inside_the_minds_of_europes_bankers_Ti nk_2019.pdf?hsCtaTracking=6835c3b3-a088-46b0-8716-729cec2f5b99\%7Cf0b32360-d50545d4-9cc6-9651c448b94f.

26. U.S. Department of the Treasury (2018) A Financial System That Creates Economic Opportunities: Nonbank Financials, Fintech and Innovation. Report to President Donald J. Trump. [Online]. Available at: https://home.treasury.gov/sites/default/files/2018-07/AFinancial-System-that-Creates-Economic-Opportunities---Nonbank-Financi....pdf.

27. Waldschmidt, M., Genthner, T. and Cortet, M. (2019) Open Banking - the Inevitable Opportunity. In: The Paypers Open Banking Report 2019: Insights into the Global Open Banking Landscape, 80-82. [Online]. Available at: https://thepaypers.com/reports/the-openbanking-report-2019-insights-into-the-global-open-banking-landscape-2/r780814. 